\title{
Activating PPM1D Gene Mutation
}

National Cancer Institute

\section{Source}

National Cancer Institute. Activating PPM1D Gene Mutation. NCI Thesaurus. Code C156761.

A change in the nucleotide sequence of the PPM1D gene that results in constitutive activation of protein phosphatase 1D and its downstream signaling pathways. 